\title{
Detection of estrous activity cycle by 1-hour samples of running behavior '
}

JOHN C. HITT, ARNOLD A. GERALL AND GERALD W. GIANTONIO TULANE UNIVERSITY

Daily $1 h$ samples of activity-wheel performance yielded activity records in which the 4-5 day estrous cycle was evident in 23 of 36 albino rats. Mean activity level was still increasing at the conclusion of 60 daily periods of measurement, but a correlational analysis revealed marked stability of relative activity level.

The periodic fluctuation in activity accompanying the rat's physiological estrous cycle has been a topic of interest since the pioneering investigations of Richter (1922), Wang (1923), and Slonaker (1924). More recently, Eayers (1954) has summarized implications of this behavioral measure and methodological considerations underlying its interpretation. In the studies examined, stable records of activity level and periodicity were obtainable after approximately 21 days of continuous $24 \mathrm{~h}$ restriction in the activity wheel apparatus. However, maintaining Ss in activity wheels $24 \mathrm{~h}$ a day is uneconomical in terms of apparatus usage and makes Ss unavailable for many experimental manipulations during the recording period. Shirley (1928) reported coefficients of correlation in excess of .90 between the mean activity level of the male rat during daily $1 \mathrm{~h}$ periods of activity wheel confinement and $24 \mathrm{~h} /$ day confinement. The following study was performed to explore the possibility of obtaining reliable estrous activity cycle data by taking daily 1 h samples during a 60 day period.

Method

The Ss, which were 36 female Sprague-Dawley rats approximately 85 days old, were housed in individual living cages in an air conditioned room where the temperature was maintained at $68^{\circ}-72^{\circ} \mathrm{F}$. After one week, the natural light cycle was replaced by a cycle of $12 \mathrm{~h}$ darkness beginning at 8:00 AM followed by $12 \mathrm{~h}$ of light. Four days after this change, Ss were unsystematically assigned to one of three groups of $12 \mathrm{Ss}$ each, for which the only procedural difference was whether their $1 \mathrm{~h}$ running period started at 9:00 AM, 10:10 AM, or 11:20 AM. Ten minutes were required for transferring Ss between the Wahmann Co. activity wheels and home cages and for data recording. Food and water were available ad lib in home cages but not in activity wheels. Results

The form of the activity cycle record obtained with a $1 \mathrm{~h}$ sample is shown in Fig. 1. While the four-five day periodicity is not as dramatically evident as that secured with $24 \mathrm{~h}$ recordings, it can be discerned by careful visual inspection of the raw data and,

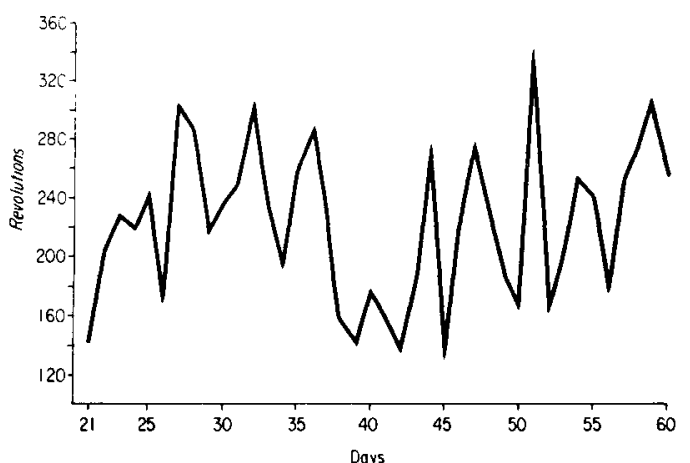

Fig. 1. Number of activity-wheel revolutions recorded during daily 1 h sessions for $\mathbf{S} 35$.

more readily, by examining power spectral estimates Blackman \& Tukey, 1958; Gerall, 1967). As presented in Fig. 2, power spectral estimates of the data shown in Fig. 1 indicate that the predominant contribution to the total variance is associated with the four day cycle, lesser amounts with the three and five day cycles. Contained in Table 1 is a summary of the dominant periodicities detected by power spectral analyses of the 36 individual records. Twenty-three exhibited a periodicity within the four-five day range characteristic of estrus, while only three exhibited no measurable periodicity. There was no significant difference in the distribution of dominant periodicities observed in the three groups $\left(X^{2}=10.12\right.$, $\left.\mathrm{df}=10\right)$, indicating that sampling in any of the second through fifth hours of darkness yields essentially identical results.

The mean activity levels of each of the three groups

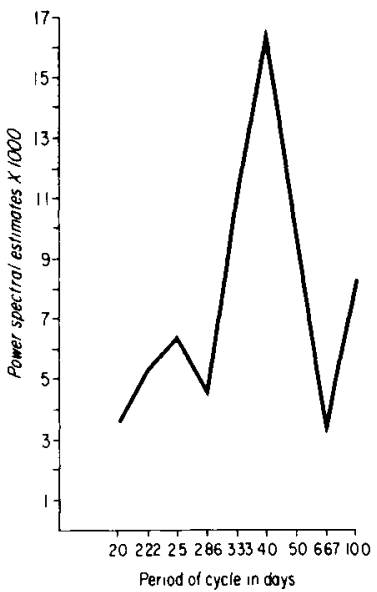

Fig. 2. Power spectral estimates for $S 35$ 's activity record. 
Table 1. Number of Ss Exhibiting Dominant Activity Cycles of Different Periods.

\begin{tabular}{llllllll}
\multicolumn{7}{c}{ Period of Cycle (Days) } \\
\hline \multicolumn{1}{c}{ Group } & 2 & 3 & 4 & 5 & 7 & No Cycle & N \\
\hline 9:00-10:00 & 0 & 0 & 4 & 5 & 2 & 1 & 12 \\
10:10-11:10 & 1 & 1 & 0 & 7 & 1 & 2 & 12 \\
11:20-12:20 & 1 & 3 & 3 & 4 & 1 & 0 & 12 \\
Total & 2 & 4 & 7 & 16 & 4 & 3 & 36 \\
\hline
\end{tabular}

are shown in Fig. 3 for each of the six successive 10 day periods of measurement. Analysis of variance revealed no significant difference among the group means $(F=0.56593, \mathrm{df}=2 / 33)$, a significant periods effect $(F=19.28695, d f=5 / 165, p<.001)$, and no significant groups by periods interaction $(F=1.17467$, $d f=10 / 165, p>.05)$. Although it is clear from Fig. 3 that the groups' activity levels were still increasing at the conclusion of 60 days of observation, the results of a correlational analysis, which are shown in Table 2, revealed a strong positive relationship between the Ss' mean activity levels during the six successive 10 day periods. Indeed, the means for Days $11-20$ and $51-60$ share over $75 \%$ common variance, and those for Days 21-30 and 51-60, over $82 \%$. A factor analysis of the matrix of intercorrelations yielded a single factor.

Discussion

That a substantial majority of Ss exhibited fourfive day periodicity in activity indicates the acceptability of daily $1 \mathrm{~h}$ measurement of activity as a technique for the detection of the estrous cycle. While there was no evidence that the Ss had approached asymptotic levels of performance, correlational analysis

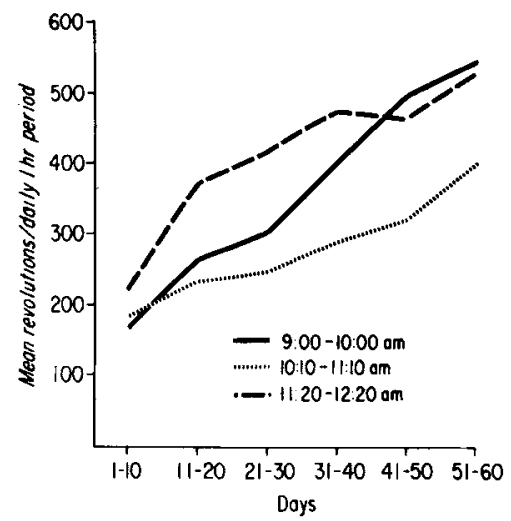

Fig. 3. Mean number of activity-wheel revolutions exhibited by the 3 groups during the 6 successive 10 day periods of daily $1 \mathrm{~h}$ measurement of activity.
Table 2. Intercorrelations between Mean Rate of Running Obtained during 6 Successive 10 day Periods of Daily $1 \mathrm{~h}$ Measurement.

\begin{tabular}{rcccccc} 
Days & $1-10$ & $11-20$ & $21-30$ & $31-40$ & $41-50$ & $51-60$ \\
\hline $1-10$ & & .89 & .80 & .81 & .80 & .77 \\
$11-20$ & & & .94 & .94 & .89 & .87 \\
$21-30$ & & & & .98 & .92 & .91 \\
$31-40$ & & & & & .96 & .94 \\
$41-50$ & & & & & & .98 \\
$51-60$ & & & & & & \\
\hline
\end{tabular}

revealed strong predictive relationships between mean activity levels throughout the course of observation. Failure to attain asymptotic levels of performance might prohibit the use of $1 \mathrm{~h}$ measurement of activity in experimental designs which assume a stable baseline, but it can be employed with confidence in its reliability in studies in which control groups are included. The detection of a single factor in the matrix of intercorrelations and the rapid rise of the coefficients of correlation to near-asymptotic values suggest that Ss require but a relatively short period of adaptation (perhaps 20 days) before reliable estimates of relative activity level are established. The absence of any statistically significant effect for time of the $1 \mathrm{~h}$ session suggests that experimental treatments need not be orthogonal to this variable. Finally, investigations in this laboratory (Hitt, 1966) have found the $1 \mathrm{~h}$ measurement technique adequate for the detection of changes in the amplitude and periodicity of the estrous activity cycle following discrete diencephalic lesions.

\section{References}

BLACKMAN, R. B., \& TUKEY, J. W. The measurement of power spectra. New York: Dover Publication, Inc., 1958.

EAYERS, J. T. Spontaneous activity in the rat. Brit. J. Anim. Behav., 1954, 2, 25-30.

GERALL, A. A. Effects of early postnatal androgen and estrogen injections on the estrous activity cycles and mating behavior of rats. Anat. Rec., 1967, 147, 97-104.

HITT, J. C. The effects of forebrain and hypothalamic lesions on estrous activity cycles in the albino rat. (Doctoral dissertation. Tulane University.) Ann Arbor, Mich.: University Microfilms, 1966. No. $67-4458$.

RICHTER, C. P. A behavioristic study of the activity of the rat. Comp. Psychol. Monogr., 1922, 1, No. 2.

SHIRLEY, M. Studies in activity. II. Activity rhythms; age and activity, after rest. $J$. comp. Psychol., 1, 159-186.

SLONAKER, J, R. The effects of pubescence, oestration, and menopause on the voluntary activity of the albino rat. Amer. J. Physiol., $68,294-315$.

WANG, G. H. Relation between "spontaneous" activity and oestrous cycle in the white rat. Comp. Psychol. Monogr., 1923, 2, 1-27. Note

1. This research was supported by Research Grant HD 00867-05 from the National Institute of Child Health and Human Development. 